\title{
Outbreak of hepatitis $\mathrm{A}$ infection associated with the consumption of frozen berries, Ireland, 2013 - linked to an international outbreak
}

\author{
M Fitzgerald (margareta.fitzgerald@hse.ie) ${ }^{1,2}$, L Thornton'1 ${ }^{1}$, O’Gorman³, L 0’Connor ${ }^{4}$, P Garvey ${ }^{1}$, M Boland ${ }^{5}$, A M Part ${ }^{6}$, J \\ Rogalska ${ }^{1,2}$, H Coughlan', J MacDiarmada ${ }^{5}$, J Heslin ${ }^{8}$, M Canny9, P Finnegan $^{10}$, J Moran ${ }^{1,3}$, D O’Flanagan', \\ on behalf of the Hepatitis A Outbreak Control Team ${ }^{11}$ \\ 1. Health Service Executive (HSE) - Health Protection Surveillance Centre (HPSC), Dublin, Ireland \\ 2. European Programme for Intervention Epidemiology Training (EPIET), European Centre for Disease Prevention and Control \\ (ECDC), Stockholm, Sweden \\ 3. National Virus Reference Laboratory (NVRL), University College Dublin, Dublin, Ireland \\ 4. Food Safety Authority of Ireland (FSAI), Dublin, Ireland \\ 5. Department of Public Health, HSE East, Dublin, Ireland \\ 6. Environmental Health Service, HSE Dublin Mid-Leinster Region, Dublin, Ireland \\ 7. Department of Public Health, HSE South, Cork, Ireland \\ 8. Department of Public Health, HSE South-East, Kilkenny, Ireland \\ 9. Department of Public Health, HSE West, Galway, Ireland \\ 10. Department of Public Health, HSE North-East, Meath, Ireland \\ 11. The members of the Outbreak Control Team are listed at the end of the article
}

Citation style for this article:

Fitzgerald M, Thornton L, O'Gorman J, O'Connor L, Garvey P, Boland M, Part AM, Rogalska J, Coughlan H, MacDiarmada J, Heslin J, Canny M, Finnegan P, Moran J, O'Flanagan D, on behalf of the Hepatitis A Outbreak Control Team. Outbreak of hepatitis A infection associated with the consumption of frozen berries, Ireland, 2013 - linked to an international outbreak. Euro Surveill. 2014;19(43):pii=20942. Available online: http://www.eurosurveillance.org/ViewArticle. aspx?Articleld $=20942$

Article submitted on 20 February 2014 / published on 30 October 2014

In May 2013, a European alert was issued regarding a hepatitis A virus (HAV) outbreak in Italy. In June 2013, HAV subgenotype IA with an identical sequence was identified in Ireland in three cases who had not travelled to Italy. The investigation consisted of descriptive epidemiology, a case-control study, microbiological testing of human and food specimens, molecular typing of positive specimens and food traceback. We identified 21 outbreak cases (14 confirmed primary cases) with symptom onset between 31 January and 11 October 2013. For the case-control study, we recruited 11 confirmed primary cases and 42 matched controls. Cases were more likely than controls to have eaten berry cheesecake (matched odds ratio (mOR): 12; 95\% confidence interval (CI):1.3-114), whole frozen berries (mOR: $9.5 ; 95 \% \mathrm{Cl}: 1.0-89$ ), yoghurt containing frozen berries (mOR: $6.6,95 \% \mathrm{Cl}: 1.2-37$ ) or raw celery (mOR: 4 ; 95\% Cl: 1.2-16). Among cases, 91\% had consumed at least one of four products containing frozen berries (mOR: $12 ; 95 \% \mathrm{Cl}: 1.5-94$ ). Sixteen food samples tested were all negative for HAV. As products containing frozen berries were implicated in the outbreak, the public were advised to heat-treat frozen berries before consumption.

\section{Background}

Hepatitis $A$ is a vaccine-preventable, self-limiting infection of the liver caused by hepatitis A virus (HAV). Infection in children is asymptomatic or associated with mild illness. In adults, the most common symptoms are fever, loss of appetite, nausea, fatigue and abdominal pain, followed within a few days by jaundice. Clinical severity varies from a relatively mild illness lasting one to two weeks to a severely disabling illness lasting months [1]. Transmission is primarily by the faecal-oral route, including person-to-person spread and contaminated food or water. The average incubation period is 28 to 30 days (range: $15-50$ days), with maximum infectivity occurring during the latter half of the incubation period and for a few days after onset of jaundice [1]. In developed countries, HAV infection rates are low and decreasing. In the European Union, the overall incidence of HAV decreased from 15.1 per 100,000 in 1996 to 3.9 per 100,000 in 2006, attributable to improved living and sanitary conditions [2]. In 2011, the incidence rate in Europe was 2.5 per 100,000 [3]. However, a reduction in the circulation of HAV leads to an accumulation of susceptible individuals in a population and allows for outbreaks to occur [2]. Foodborne transmission of HAV has been associated with several outbreaks in recent years in Europe, Australia and the United States (US); the implicated foods included fish and seafood products, vegetables, juices, semi-dried tomatoes, berries [4] and pomegranate seeds $[5,6]$.

Since 1981, HAV infections have been notifiable in Ireland by clinicians. Since 2004, laboratories have also been required to notify. The incidence of HAV in Ireland has fallen substantially from a peak of 16 per 100,000 population (564 cases) in 1989 to 0.7 per 100,000 population (30 cases) in $2012[7,8]$. The HAV 
vaccine is not included in the Irish childhood immunisation programme. From 2004 (when outbreaks of infectious diseases became notifiable) to the end of $\mathbf{2 0 1 2}$, no foodborne outbreaks due to HAV were reported in Ireland. Before 2013, molecular investigation of HAV cases was not routinely available in Ireland.

In April 2013, a European alert was issued relating to an outbreak of HAV subgenotype IB in four Nordic countries [9]. Frozen berries were later found to be the likely vehicle of infection [10]. A second alert due to an outbreak of HAV subgenotype IA associated with travel to Italy was issued in May 2013 [11]. Between January and May 2013, 352 cases of HAV infection were notified in Italy corresponding to a $70 \%$ increase compared to the same period in 2012, and preliminary investigations indicated mixed frozen berries as the most likely vehicle of infection [12]. Following these alerts, a decision was taken in Ireland to retrospectively and prospectively genotype and sequence all available samples from serologically confirmed cases of HAV infection since the beginning of 2013. In June 2013, three HAV cases from Ireland were identified as subgenotype IA, a strain identical to the one occurring in the Italian outbreak (GenBank accession number: KF182323) [12]. None of the cases had a history of travel to Italy. An outbreak investigation commenced and a multidisciplinary outbreak control team was established.

The objectives of our investigation were to describe the outbreak in order to determine its extent and to identify the vehicle and source in order to implement control measures.

\section{Methods}

\section{Case definition}

A confirmed outbreak case was defined as a person living in Ireland with a laboratory-confirmed (HAV IgM and HAV RNA PCR-positive) infection of HAV subgenotype IA with a sequence identified by GenBank accession number KF182323 and with onset of symptoms from 1 January 2013. Cases who had travelled to Italy were excluded. A possible case was the same as a confirmed case, except the genotype and sequence type were unknown and the person had not travelled outside Europe to a country of high endemicity.

A secondary case was defined as a confirmed or possible case with symptom onset two to seven weeks after close contact with a primary confirmed or possible case.

\section{Case finding and descriptive epidemiology}

Cases were identified using the mandatory notification system in conjunction with the genotyping and sequencing results reported by the National Virus Reference Laboratory (NVRL). We sent alerts to Departments of Public Health, general practitioners, hepatologists, emergency department physicians, infectious diseases consultants and microbiologists, informing them of the outbreak and reminding them to notify HAV cases.

\section{Case-control study}

Public health personnel undertook telephone interviews with the first 10 cases using a detailed trawling questionnaire which included questions on exposures previously associated with HAV infections. We generated hypotheses based on data obtained from the trawling questionnaires. Our resulting primary hypothesis was that illness was associated with the consumption of frozen berries. Other hypotheses were also considered, including illness being associated with the consumption of fresh berries, or specifically fresh blueberries.

We conducted a matched case-control study to test these hypotheses. Only confirmed primary cases were eligible. Controls were randomly selected using random digit dialling of landline and mobile telephone numbers, matched on age ( \pm 5 years), sex and county of residence. A market research company recruited the controls for the study according to an agreed protocol. Investigators from the Departments of Public Health and Health Protection Surveillance Centre (HPSC) interviewed study participants by telephone using a pre-tested questionnaire, which included questions on the consumption of fresh berries, frozen berries, various frozen-berry products, pomegranate, salad items, shellfish and raw seafood, and details on the place of purchase and brands of these items. Cases were asked about their exposures in the seven weeks before onset of symptoms and controls were asked about their exposures in the same time period as their matched case. Controls were excluded if they were vaccinated against HAV, had previously been diagnosed with HAV (self-reported) or lived in the same household as an HAV case in 2013. Interviews were completed on three or four controls per case.

\section{Data analysis}

We described the distribution of cases notified on the national Computerised Infectious Diseases Reporting (CIDR) system for notifiable infectious diseases by time, place, person and case classification. We entered the questionnaire responses from the case-control study into an EpiData database (Epidata association, Denmark, version 3.1) and analysed them using Stata 11.2 (Stata Corporation,Texas, US).

The association between illness and food items consumed was estimated by calculating crude matched odds ratios (mOR) and 95\% confidence intervals (CI). Subsequently, we conducted conditional logistic regression to identify independent risk factors for the disease. We constructed initial models including variables with a $p$ value $\leq 0.25$ in the univariate analysis. To simplify the model, variables were removed one at a time depending on the significance testing, using likelihood ratio tests. An association was considered statistically significant when $\mathrm{p} \leq 0.05$. 
Distribution of hepatitis A outbreak cases by week of onset of symptoms, Ireland, 2013 ( $\mathrm{n}=21$ )

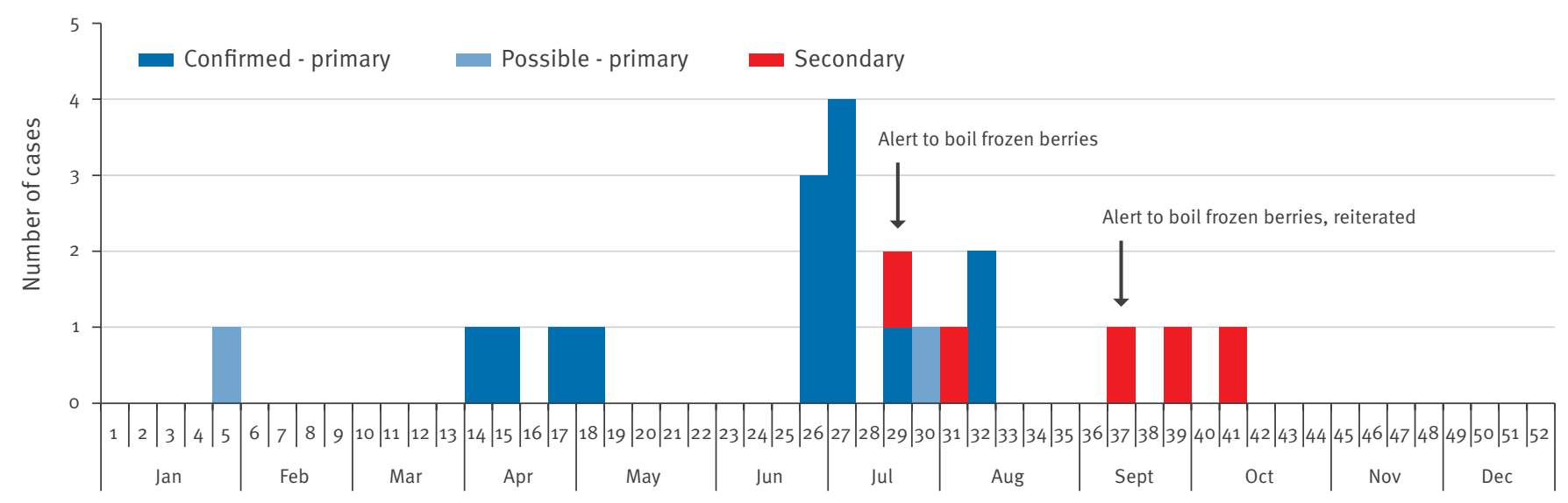

Week of onset of symptoms in 2013

\section{Microbiological investigation}

The diagnosis of acute HAV infection was established by serological testing for anti-HAV IgM at local laboratory level. Additional serological and molecular investigations using an in-house real-time PCR assay for HAV RNA was performed at the NVRL. Following detection of HAV RNA in serum, molecular sequencing was performed. In the initial stages of the outbreak, HAV RNA sequence analysis was not available in Ireland and therefore the Virus Reference Department, Public Health England (PHE) performed these investigations. Subsequently, HAV molecular sequencing was introduced in the NVRL, consisting of nested reverse transcriptase PCR (RT-PCR) to amplify a ca 400 bp region in the $\mathrm{VP}_{1} / 2 \mathrm{PA}$ region of the HAV genome [13]. Sanger sequencing and phylogenetic analysis was performed to characterise HAV sequences.

Selected food samples from food companies and cases' freezers were sent to the Istituto Zooprofilattico Sperimentale in Italy for analysis as no laboratory in Ireland currently conducts testing for HAV in berries. The samples were analysed using a nested PCR method.

\section{Trace-back investigation}

Suspect foods identified in the trawling questionnaires and the case-control study were investigated by Health Service Executive (HSE) Environmental Health Officers, the Department of Agriculture Food and Marine (DAFM) and the Food Safety Authority of Ireland (FSAI). Traceback and traceforward information was obtained from retailers, manufacturers, distributors and importers. Traceability information of foods imported into Ireland was obtained using the European Commission's Rapid Alert System for Food and Feed (RASFF).

\section{Results}

\section{Descriptive epidemiology}

In total, 50 cases of HAV infection were notified in Ireland in 2013 and 21 cases met the outbreak case definition (14 confirmed primary, two possible primary and five secondary). Cases were distributed nationally, occurring in five of the eight health regions. Cases ranged in age from 25 to 64 years (median age 35 years) and 12 of 21 were female. Twelve cases were hospitalised and the median length of hospital stay was five days (range: 1-9 days). There were no deaths. Among the 14 confirmed primary cases, there were two clusters in time; one cluster of four cases with onset of symptoms in April and a second cluster of 10 cases with onset of symptoms between 24 June 2013 and 9 August 2013 (Figure).

\section{Case-control study}

Of the 14 confirmed primary cases eligible for the case-control study, 11 participated and three declined. A total of 42 controls were included, with three or four matched controls per case. Cases were significantly more likely than controls to have consumed cheesecake containing frozen berries $(\mathrm{mOR}=12 ; 95 \% \mathrm{Cl}$ : 1.3-115), whole frozen berries ( $\mathrm{mOR}=9.5 ; 95 \% \mathrm{Cl}: 1.0-$ 89 ), a particular yoghurt (yoghurt A) containing frozen berries $(\mathrm{mOR}=6.6 ; 95 \% \mathrm{Cl}: 1.2-37)$ and raw celery ( $\mathrm{mOR}=4,95 \% \mathrm{Cl}: 1.2-16)$ (Table 1). The cheesecakes containing frozen berries consumed by the cases and controls were store-bought. Yoghurt A is a commercial product available in stores nationwide. The consumption of fresh berries or fresh blueberries was not significantly associated with illness. In the conditional regression analysis, only cheesecake containing frozen berries remained significant in the final model. However, four of 10 cases for whom this information was available, had consumed this item (Table 1 ). 
TABLE 1

Food exposures among hepatitis A subgenotype IA cases $(n=11)$ and controls $(n=42)$, Ireland, 2013

\begin{tabular}{|c|c|c|c|c|c|c|c|c|c|}
\hline \multirow{2}{*}{$\begin{array}{l}\text { Exposure } \\
\text { Total }\end{array}$} & \multicolumn{3}{|c|}{ Cases } & \multicolumn{3}{|c|}{ Controls } & \multirow{2}{*}{$\begin{array}{l}\text { Crude } \\
\text { mOR }\end{array}$} & \multirow{2}{*}{$95 \% \mathrm{Cl}$} & \multirow{2}{*}{$\mathrm{p}$ value } \\
\hline & Total $^{a}$ & Exposed & $\%$ & Total & Exposed & $\%$ & & & \\
\hline \multicolumn{10}{|l|}{ Individual products } \\
\hline Cheesecake $^{\mathrm{b}}$ & 10 & 4 & 40 & 42 & 4 & 10 & 12 & $1.3-114$ & 0.026 \\
\hline Celery & 11 & 6 & 55 & 42 & 7 & 17 & 4.0 & $1.2-16$ & 0.026 \\
\hline Whole frozen berries & 10 & 4 & 40 & 42 & 4 & 10 & 9.5 & $1.0-89$ & 0.031 \\
\hline Yoghurt $A^{b}$ & 10 & 4 & 40 & 42 & 3 & 7 & 6.6 & $1.2-37$ & 0.048 \\
\hline Fresh blueberries & 11 & 9 & 82 & 42 & 22 & 52 & 4.1 & $0.79-21$ & 0.093 \\
\hline Ice creamb & 11 & 2 & 18 & 42 & 1 & 2 & 7.3 & $0.66-81$ & 0.105 \\
\hline Yoghurts $^{\mathrm{b}, \mathrm{c}}$ & 10 & 5 & 50 & 42 & 9 & 21 & 3.1 & $0.77-12$ & 0.112 \\
\hline Smoothies ${ }^{b}$ & 9 & 4 & 44 & 42 & 9 & 21 & 3.1 & $0.67-14$ & 0.151 \\
\hline Fresh berries & 11 & 10 & 91 & 42 & 33 & 79 & 3.4 & $0.30-38$ & 0.321 \\
\hline \multicolumn{10}{|l|}{ Grouped products } \\
\hline Cheesecake or yoghurt $\mathrm{A}$ & 10 & 6 & 60 & 42 & 7 & 17 & $5 \cdot 3$ & $1.3-22$ & 0.023 \\
\hline Whole frozen berries or yoghurt $A$ & 10 & 6 & 60 & 42 & 7 & 17 & 7.0 & $1.4-37$ & 0.02 \\
\hline Cheesecake or whole frozen berries & 10 & 7 & 70 & 42 & 7 & 17 & 14 & $1.7-122$ & 0.014 \\
\hline Cheesecake or whole frozen berries or yoghurt $A$ & 10 & 8 & 80 & 42 & 10 & 24 & 8.1 & $1.6-40$ & 0.011 \\
\hline $\begin{array}{l}\text { Cheesecake or whole frozen berries or yoghurt A } \\
\text { or smoothies }{ }^{d}\end{array}$ & 11 & 10 & 91 & 42 & 16 & 38 & 12 & $1.5-94$ & 0.02 \\
\hline
\end{tabular}

$\mathrm{Cl}$ : confidence interval;.mOR: matched odds ratio.

a Cases with available information.

b These products contained frozen berries.

Includes yoghurt $A$ and other yoghurts containing frozen berries.

d No change when ice-cream was added to this combination.

When products containing frozen berries (i.e. whole frozen berries or cheesecake or yoghurt A or smoothies) were grouped together, cases were more likely than controls to have consumed at least one of the products within the group ( $\mathrm{mOR}=12 ; 95 \% \mathrm{Cl}: 1.5-94)$, with 10 of 11 cases exposed (Table 1 ).

The odds of the illness increased with increasing frequency of consumption of yoghurt $A$ and smoothies (Table 2). No frequency response could be calculated for cheesecake, while a frequency response effect was not demonstrated with celery (Table 2).

\section{Microbiological analysis}

Of the $21 \mathrm{HAV}$ cases, 18 were sequenced and genotyped (14 primary and four secondary). HAV RNA sequences from these cases had a $100 \%$ nucleotide homology to the HAV IA outbreak strain over the region sequenced.

In total, 16 food items which included frozen berries, products containing frozen berries and fresh berries were tested. HAV RNA was not detected in any of these food samples. Samples included two batches of frozen mixed berries used in batches of yoghurt A potentially consumed by some cases and a third batch to which cases could not have been exposed.
Traceback analysis

The Italian authorities had detected HAV in frozen berries imported to Italy with a sequence identical to the Irish outbreak strain [4]. Therefore, the traceback investigations in Ireland focused on the imported frozen berry supply chain, but fresh berries and other foods consumed by cases were also investigated.

The investigations found that products from a single Irish distributor of imported frozen berries had been used in foods consumed by nine of the 14 primary cases eligible for the case-control study. A comparison with the Italian traceability investigation, however, has not to date identified an overlap in the supply chain that could explain the source of the outbreak in both countries.

The traceback investigation on fresh berries did not point to a common point source.

Control measures

Prophylactic human normal immunoglobulin and/or HAV vaccine were offered to close contacts of cases as necessary. Advice about hygiene and exclusion from schools or childcare facilities and certain workplaces was also provided to cases and their contacts.

On 4 June 2013, the FSAI issued an information note to food business operators in Ireland regarding the 
Frequency of consumption of selected food items among hepatitis A subgenotype IA cases $(\mathrm{n}=11)$ and controls $(\mathrm{n}=42)$, Ireland, 2013

\begin{tabular}{|c|c|c|c|c|c|c|c|c|c|}
\hline \multirow{2}{*}{ Exposure / frequency } & \multicolumn{3}{|c|}{ Cases } & \multicolumn{3}{|c|}{ Controls } & \multirow{2}{*}{ Crude mOR } & \multirow{2}{*}{$95 \% \mathrm{Cl}$} & \multirow{2}{*}{$\mathrm{p}$ value } \\
\hline & Total & Exposed & $\%$ & Total & Exposed & $\%$ & & & \\
\hline \multicolumn{10}{|l|}{ Yoghurt $A^{a}$} \\
\hline $\begin{array}{l}\text { Never } \\
\text { く1 weekly } \\
\geq 1 \text { weeklyc }^{\mathrm{c}}\end{array}$ & $\begin{array}{l}10 \\
10 \\
10 \\
\end{array}$ & $\begin{array}{l}6 \\
1 \\
3 \\
\end{array}$ & $\begin{array}{l}60 \\
10 \\
30 \\
\end{array}$ & $\begin{array}{l}42 \\
42 \\
42 \\
\end{array}$ & $\begin{array}{c}39 \\
2 \\
1 \\
\end{array}$ & $\begin{array}{c}93 \\
5 \\
2 \\
\end{array}$ & $\begin{array}{c}\text { Ref } \\
2.9 \\
12 \\
\end{array}$ & $\begin{array}{c}- \\
0.23-36 \\
1.2-125 \\
\end{array}$ & $\begin{array}{c}- \\
0.406 \\
0.032 \\
\end{array}$ \\
\hline \multicolumn{10}{|l|}{ Smoothies ${ }^{a}$} \\
\hline $\begin{array}{l}\text { Never } \\
<1 \text { weekly }^{\mathrm{b}} \\
\geq 1 \text { weekly }^{\mathrm{c}}\end{array}$ & $\begin{array}{l}9 \\
9 \\
9 \\
\end{array}$ & $\begin{array}{l}4 \\
2 \\
3 \\
\end{array}$ & $\begin{array}{l}45 \\
22 \\
33\end{array}$ & $\begin{array}{l}42 \\
42 \\
42 \\
\end{array}$ & $\begin{array}{c}33 \\
5 \\
4 \\
\end{array}$ & $\begin{array}{c}79 \\
12 \\
9 \\
\end{array}$ & $\begin{array}{l}\text { Ref } \\
2.7 \\
5.9 \\
\end{array}$ & $\begin{array}{c}- \\
0.40-19 \\
0.90-38 \\
\end{array}$ & $\begin{array}{c}- \\
0.307 \\
0.064 \\
\end{array}$ \\
\hline \multicolumn{10}{|l|}{ Whole frozen berries } \\
\hline $\begin{array}{l}\text { Never } \\
\text { く1 weekly } \\
\geq 1 \text { weekly }^{\mathrm{c}}\end{array}$ & $\begin{array}{l}10 \\
10 \\
10 \\
\end{array}$ & $\begin{array}{l}6 \\
2 \\
2\end{array}$ & $\begin{array}{l}60 \\
20 \\
20\end{array}$ & $\begin{array}{l}42 \\
42 \\
42 \\
\end{array}$ & $\begin{array}{c}38 \\
2 \\
2 \\
\end{array}$ & $\begin{array}{c}90 \\
5 \\
5\end{array}$ & $\begin{array}{l}\text { Ref } \\
9.5 \\
9.5\end{array}$ & $\begin{array}{c}- \\
0.61-148 \\
0.61-148 \\
\end{array}$ & $\begin{array}{c}- \\
0.107 \\
0.107 \\
\end{array}$ \\
\hline \multicolumn{10}{|l|}{ Cheesecake $^{a}$} \\
\hline $\begin{array}{l}\text { Never } \\
<1 \text { weekly }^{\mathrm{b}} \\
\geq 1 \text { weekly }^{\mathrm{c}}\end{array}$ & $\begin{array}{l}10 \\
10 \\
10 \\
\end{array}$ & $\begin{array}{l}6 \\
3 \\
1 \\
\end{array}$ & $\begin{array}{l}60 \\
30 \\
10 \\
\end{array}$ & $\begin{array}{l}42 \\
42 \\
42 \\
\end{array}$ & $\begin{array}{c}38 \\
4 \\
0 \\
\end{array}$ & $\begin{array}{l}91 \\
9 \\
0 \\
\end{array}$ & $\begin{array}{l}\text { Ref } \\
8.6 \\
\mathrm{NC}\end{array}$ & $\begin{array}{c}- \\
0.85-86 \\
\mathrm{NC}\end{array}$ & $\begin{array}{c}- \\
0.068 \\
N C\end{array}$ \\
\hline \multicolumn{10}{|l|}{ Celery } \\
\hline $\begin{array}{l}\text { Never } \\
<1 \text { weekly }^{\mathrm{b}} \\
\geq 1 \text { weekly }^{\mathrm{c}}\end{array}$ & $\begin{array}{l}10 \\
10 \\
10\end{array}$ & $\begin{array}{l}5 \\
2 \\
3\end{array}$ & $\begin{array}{l}50 \\
20 \\
30\end{array}$ & $\begin{array}{l}42 \\
42 \\
42 \\
\end{array}$ & $\begin{array}{c}35 \\
1 \\
6 \\
\end{array}$ & $\begin{array}{c}83 \\
3 \\
14\end{array}$ & $\begin{array}{l}\text { Ref } \\
8.1 \\
2.4\end{array}$ & $\begin{array}{c}- \\
0.72-92 \\
0.51-12 \\
\end{array}$ & $\begin{array}{c}- \\
0.091 \\
0.267\end{array}$ \\
\hline
\end{tabular}

$\mathrm{Cl}$ : confidence interval;.mOR: matched odds ratio; NC: non calculable.

a These products contained frozen berries.

${ }^{b}$ Ranged from once in seven week period to two to three times per month.

c Ranged from one to two times per week to five or more times per week.

potential risk posed by imported frozen berries. This was based on information from the Nordic and the Italian outbreak investigations. On 19 July 2013, following the identification of HAV cases in Ireland with a strain identical to the Italian outbreak strain, the FSAl issued a press release advising consumers and food business operators, as a precautionary measure, to boil imported frozen berries for one minute before consumption[14]. At the same time, the FSAl issued a second information note to food business operators reminding them to source berries from reputable suppliers with efficient and comprehensive traceability systems and effective food safety management systems. Furthermore, food business operators were advised that if they had any concerns regarding the source of the berries, they should boil the berries before inclusion in uncooked products. The advice to consumers and food business operators was reiterated by the FSAI on 8 September 2013.

\section{Discussion}

We report on a foodborne outbreak of HAV subgenotype IA infection in Ireland. Nucleic acid sequences of HAV RNA were identical, indicating that cases were likely to have been infected from a common source. The outbreak strain was identical to the one in a concurrent but separate foodborne outbreak in Italy. We present epidemiological evidence that the HAV subgenotype IA outbreak in Ireland was associated with the consumption of products containing frozen berries. Traceback investigations at an international level, coordinated by the European Food Safety Authority, to identify the origins of the imported frozen berries failed to identify a single point source of contamination [15].

Our case-control study revealed that no single product explained the majority of the cases. Although the consumption of cheesecake containing frozen berries remained significantly associated with illness in the multivariable analysis, the product was consumed by a relatively small proportion ( $40 \%$ ) of the cases. Yoghurt $A$ and smoothies were found not to be individually associated with illness in the final multivariable model; however, a frequency response effect was demonstrated for both of these products. When frozen berry products were grouped together in the analysis, a strong and significant association was shown between the consumption of the grouped products and HAV subgenotype IA infection of the same sequence type. All but one of the 11 cases had consumed at least one of the frozen berry-containing products in the group: cheesecake, yoghurt A, smoothies or whole frozen berries.

Mixed frozen berries were also identified as the potential vehicle of infection in the related Italian outbreak [12]. Furthermore, specific frozen berries were implicated in several other HAV outbreaks including frozen 
strawberries in Nordic countries in 2013 [16] and in the US in 1997 and 1992 [17,18] and frozen raspberries in Scotland in 1987 and 1983 [19,20]. Pomegranate seeds were implicated in HAV outbreaks in the US in 2013 and Canada in 2012 [5,6]. Fresh berries have also been associated with hepatitis $A$ infections, including an outbreak in New Zealand linked to the consumption of blueberries [21].

Raw celery consumption was also significantly associated with being a case in the univariate analysis, but did not remain significant in the multivariable analysis. Six of the cases had consumed raw celery over a fivemonth period. However, since celery is a fresh product with a short shelf life, it is highly unlikely to be the source such a prolonged outbreak or indeed an embedded secondary outbreak. In contrast a frozen product such as frozen berries, with a long shelf life explains a long outbreak such as this one very well.

The selection and recruitment of controls for casecontrol studies can be difficult and resource-intensive, particularly as Ireland does not have a national population registry. In this analytical study, the novel use of a market research company to recruit by random digit dialling proved efficient and effective, although matching of controls to the county of residence of the cases prolonged the process (personal communication: Sonya McGuirl, Millward Brown, Dublin, October 2013). Almost 1,900 calls were made to recruit sufficient controls, which equated on average to one hour of calls per control recruited.

The sequencing and genotyping of HAV RNA from the cases was crucial in identifying a national outbreak and in establishing a link with the Italian outbreak. Rapid and comprehensive referral of samples from local laboratories to the NVRL and PHE for HAV RNA PCR and molecular sequencing as well as international collaboration with laboratory colleagues in PHE, Colindale and the Hepatitis A Laboratory Network (HAV-NET) group played a vital role in the identification and investigation of this outbreak against the backdrop of an increasingly globalised food production industry.

We did not obtain confirmatory microbiological evidence from the food to support the epidemiological findings; in many cases the implicated batch was no longer available for testing, due to the long incubation period for HAV. The microbiological investigation was further complicated by limitations in food testing capability in Ireland. Consequently, only a limited number of food samples could be tested by an external laboratory. Despite the lack of confirmatory microbiological evidence from the food in Ireland, indirect evidence was available. HAV was identified in a number of frozen berry samples in connection with the outbreak in Italy and the identical sequence to the outbreak strain was confirmed in one sample [4].
The long incubation period for HAV infection also hampered the traceback investigations. In most cases the traceback focused on food batches delivered over several weeks rather than on specific batches consumed by cases. In addition, the frozen berry supply chain is complex, further challenging the traceability investigation. An overlap in the supply chain between Ireland and Italy has not been found, although the outbreak strains were identical and epidemiological evidence had been obtained in both countries for a link with imported frozen berries. In autumn 2013, the Netherlands reported an outbreak with the identical strain and at the request of the European Commission, the European Food Safety Authority (EFSA) co-ordinated an investigation, in collaboration with the European Centre for Disease Prevention and Control (ECDC) and European Union (EU) Member States in order to help identify the origin of these HAV subgenotype IA outbreaks [15]. Between January 2013 and June 2014, 1,444 cases of HAV potentially linked to the outbreak were reported by 12 Member States; Italy reported $90 \%$ of the cases [15]. Apart from Ireland, seven other Member States reported cases with no travel history to Italy but with a sequence identical to the GenBank accession number KF182323 strain [15], including an outbreak in Norway where the likely vehicle was a cake containing a frozen berry mix [22]. No single point source of contamination linking all cases and contaminated batches identified during the multinational outbreak could be determined [15].

When the Irish outbreak was declared over in late October 2013, the advice to boil berries before consumption was reviewed. Due to ongoing outbreaks in other EU countries indicating that contaminated product was still available, the FSAl's precautionary advice to boil imported frozen berries remained in place. A fourth information note was issued on 8 November 2013, reiterating advice to food business operators that they should boil the berries before inclusion in uncooked products if they had any concerns regarding the source of the berries.

There are a number of limitations in this investigation. One limitation of the analytical study was participant recall because of the long incubation period for HAV infection. In addition, because sequencing was carried out retrospectively on specimens from the earlier cases, there was an additional time lag before these cases and their matched controls were interviewed. Another limitation was that public health warnings were issued before the case-control study was conducted and may have introduced some recall bias. A further limitation of this investigation was that whole genome sequencing of the HAV isolates was not performed. This service is currently not available in Ireland. It is acknowledged that using sequence information from subgenomic regions to track HAV transmission may be misleading when applied to HAV strains with unknown epidemiological association [23]. As whole genome sequencing provides a more complete genetic characterisation of 
HAV strains, its use in investigating suspected foodborne outbreaks has been recommended $[23,24]$.

Despite excluding vaccinated controls or those with a history of HAV disease, immune controls as a result of infection in early childhood may have been included, which would have resulted in a bias towards the null hypothesis. Misclassification of belonging to the outbreak was minimised as all cases included in the analytical study were infected with HAV of the same sequence and genotype, and several exclusion criteria were used for the controls.

\section{Conclusion}

In conclusion, this outbreak and other HAV outbreaks in Europe in 2013-14 have highlighted the risk of HAV infection associated with the consumption of imported frozen berries. Owing to the complex supply chain it was not possible to identify the origin of the contaminated berries despite a concerted action at European level to comprehensively investigate the supply chain. However, the investigation identified critical risk factors for contamination by HAV and recommended preventative measures to be taken to minimise the risk and to protect consumers in Europe from the risks posed by contaminated frozen berries. Consumers can also protect themselves by boiling frozen berries, and food businesses that are unable to use boiled frozen berries in their products should take measures to ensure that the berries are sourced from suppliers where strict hygiene is implemented at harvest and during processing.

Members of the Outbreak Control Team (in addition to the main authors)

Mary Kieran, Marrita Mahon, Heidi Pelly (HSE-Departments of Public Health).

Deirdre Lucey, Tom Maguire, Siobhan Murphy, Kathleen Clifford, Ken Byrne, Elaine Fleming, John Maher, Aine Lynch, Caroline Smith, Shane O'Flynn (HSE-Environmental Health Service).

Martine Brennan, Amy Fitzpatrick, Wayne Anderson (Food Safety Authority of Ireland).

Fiona Cloak (HSE-Health Protection Surveillance Centre).

Siew Lin Ngui (External Adviser to the Outbreak Control Team, Virus Reference Department, Public Health England, Colindale, UK).

\section{Acknowledgements}

This article has been written on behalf of the Outbreak Control Team (membership outlined above). The authors thank the following for their contributions to the outbreak investigation: staff in the Health Service Executive (HSE) Departments of Public Health and Environmental Health Service i.e. Mary Conlon, Diana Kiely, Eleanor McArdle, Ruth McDermott, Jackie McElhinney and Grainne Parker for interviewing the cases; Sonya McGuirl at Millward Brown for co-ordinating the recruitment of controls; Paula Flanagan, HPSC for conducting control interviews; staff in the HSE Environmental Health Service and the Department of Agriculture, Food and the Marine for their work in the environmental/traceback investigations; staff at HPSC for supporting the outbreak investigation, Sarah Jackson, Margaret Mclver, Paul McKeown,
Jolita Mereckiene and Niamh Murphy; Jonathan Dean, Molecular Research Unit, NVRL for validating the Irish HAV genotyping protocol; colleagues in Irish laboratories who referred HAV positive IgM specimens to the NVRL for PCR and genotyping; staff at FSAI for supporting the outbreak investigation, Ray Ellard, Eithne Fox, Kaiu Jaago, Dorothy Guina Dornan, Alan Reilly, Jane Ryder, Ana Canizares, Pippa Haughton, Eileen Lippert and the FSAI Advice Line team; Nadia Losio of the Istituto Zooprofilattico Sperimentale, Brescia, Italy for testing the food for the presence of HAV; Niamh Phillips of the Public Health Microbiology Laboratory at St Finbarr's Hospital, Cork for facilitating the transport of food samples to Italy; Ettore Severi (ECDC) for facilitating communications between affected Member States; Caterina Rizzo (Istituto Superiore di Sanità, Italy) for sharing information on the Italian outbreak; Jeff Connell, NVRL for reviewing the manuscript; EPIET co-ordinators Kostas Danis for advice on the case-control study and the statistical analysis and comments on the manuscript and Pawel Stefanoff for advice on the case-control study.

Conflict of interest

None declared.

Authors' contributions

All authors contributed to the writing of this manuscript and approved the final version. MF led the case-control study, analysed the data and drafted the manuscript as lead writer. LT led and chaired the Outbreak Control Team, coordinated the investigation at national level, contributed to the design of the case-control study, contributed to and advised on the manuscript. JOG was in charge of the laboratory typing of human cases, contributed to the design of the case-control study and contributed to and advised on the manuscript. LOC was in charge of the traceback, contributed to the design of the case-control study and contributed to and advised on the manuscript. PG was responsible for the descriptive epidemiology, contributed to the design of the case-control study and advised on the manuscript.

$J R$ contributed to the design of the case-control study, designed the database and advised on the manuscript. AMP managed the environmental investigations and advised on the manuscript. MB, JMcD, HC, JH, MC and PF coordinated the investigation at local level, contributed to the design of the case-control study and advised on the manuscript. JM was responsible for the laboratory reporting of cases, contributed to the descriptive epidemiology and advised on the manuscript. DOF chaired the Outbreak Control Team (in LT's absence) and advised on the manuscript.

\section{References}

1. Heymann DL, editor. Control of Communicable Diseases Manual. 19th ed. Washington, D.C.: American Public Health Association; 2008

2. Payne L, Coulombier D. Hepatitis A in the European Union: responding to challenges related to new epidemiological patterns. Euro Surveill. 2009;14(3):19101. Available from: PMID:19161730

3. European Centre for Disease Prevention and Control (ECDC). Annual Epidemiological Report 2013. Reporting on 2011 surveillance data and 2012 epidemic intelligence data. Stockholm: ECDC; 2013. Available from: http://www. ecdc.europa.eu/en/publications/Publications/annualepidemiological-report-2013.pdf

4. European Centre for Disease Prevention and Control (ECDC) and European Food Safety Authority. (EFSA). Outbreak of hepatitis A virus infection in Italy and Ireland. Stockholm: ECDC; 2013. Available from: http://ecdc.europa.eu/en/publications/ publications/roa-update_hav_italy_ireland-final.pdf 
5. Centers for Disease Control and Prevention (CDC). Multistate outbreak of hepatitis A virus infections linked to pomegranate seeds from Turkey (Final Update). Atlanta: CDC. [Accessed: 10 Jan 2014]. Atlanta, CDC. Available from: http://www.cdc.gov/ hepatitis/outbreaks/2013/a1b-03-31/index.html

6. Swinkels HM, Kuo M, Embree G. Fraser Health Environmental Health Investigation Team, Andonov A, Henry B, et al. Hepatitis A outbreak in British Columbia, Canada: the roles of established surveillance, consumer loyalty cards and collaboration, February to May 2012. Euro Surveill. 2014;19(18):20792. http://dx.doi.org/10.2807/1560-7917. ES2014.19.18.20792. PMID:24832119 http://dx.doi.org/10.2807/1560-7917.ES2014.19.18.20792

7. National Disease Surveillance Centre (NDSC). Annual Report 2003. Viral hepatitis, 2003. Dublin: NDSC; 2004. Available from: http://www.hpsc.ie/hpsc/AboutHPSC/AnnualReports/ File,952,en.pdf

8. Health Protection Surveillance Centre (HPSC). Annual Report 2012. Hepatitis A. Dublin: HPSC; 2013. Available from: http:// www.hpsc.ie/hpsc/AboutHPSC/AnnualReports/File,14421,en. pdf

9. European Centre for Disease Prevention and Control (ECDC) and European Food Safety Authority. (EFSA). Outbreak of hepatitis $A$ virus infection in four Nordic countries. 15 April 2013. Joint ECDC-EFSA rapid outbreak assessment. Stockholm: ECDC; 2013 . Available from: http://www.ecdc.europa.eu/en/ publications/publications/hepatitis-a-rapid-assessmentnordic-countries-april2013.pdf

10. Gillesberg Lassen S, Soborg B, Midgley SE, Steens A, Vold L, Stene-Johansen K, et al. Ongoing multi-strain food-borne hepatitis A outbreak with frozen berries as suspected vehicle: four Nordic countries affected, October 2012 to April 2013. Euro Surveill. 2013;18(17):20467. Available from: PMID:23647625

11. European Centre for Disease Prevention and Control (ECDC) and European Food Safety Authority. (EFSA). Outbreak of hepatitis $A$ virus infection in residents and travellers to Italy. 28 May 2013. Rapid outbreak assessment. Stockholm: ECDC; 2013. Available from: http://www.ecdc.europa.eu/en/publications/ Publications/hepatitis-A-outbreak-of-hepatitis-A-virusinfection-in-residents-and-travellers-to-Italy.pdf

12. Rizzo C, Alfonsi V, Bruni R, Busani L, Ciccaglione A, De Medic $D$, et al. Ongoing outbreak of hepatitis A in Italy: preliminary report as of 31 May 2013. Euro Surveill. 2013;18(27):20518. Available from: http://dx.doi.org/10.2807/1560-7917. ES2013.18.27.20518 PMID:23870075 http://dx.doi. org/10.2807/1560-7917.ES2013.18.27.20518

13. Stene-Johansen K, Skaug K, Blystad H, Grinde B. The Hepatitis A Study Group. A unique hepatitis A virus strain caused an epidemic in Norway associated with intravenous drug abuse. Scand J Infect Dis. 1998;30(1):35-8. Available from: http:// dx.doi.org/10.1080/003655498750002277 PMID:9670356 http://dx.doi.org/10.1080/003655498750002277

14. Food Safety Authority of Ireland (FSAI). Outbreak of hepatitis A virus linked to imported frozen berries. Press release $19 \mathrm{Ju}$ 2013. Available from: http://www.fsai.ie/news_centre/press releases/Hepatitis_A_outbreak_frozen_berries_190713.htmi

15. European Food Safety Authority (EFSA). Tracing of food items in connection to a multinational hepatitis A virus outbreak in Europe. EFSA Journal 2014;12(9):3821. Available from: http:// www.efsa.europa.eu/en/efsajournal/pub/3821.htm

16. Nordic Outbreak Investigation Team. Joint analysis by the Nordic countries of a hepatitis A outbreak, October 2012 to June 2013: frozen strawberries suspected. Euro Surveill. 2013;18(27):20520. Available from: http://dx.doi. org/10.2807/1560-7917.ES2013.18.27.20520 PMID:23870076 http://dx.doi.org/10.2807/1560-7917.ES2013.18.27.20520

17. Hutin YJ, Pool V, Cramer EH, Nainan OV, Weth J, Williams IT, et al. National Hepatitis A Investigation Team. A multistate, foodborne outbreak of hepatitis A. N Engl J Med. 1999;340(8):595-602. Available from: http://dx.doi. org/10.1056/NEJM199902253400802 PMID:10029643 http:// dx.doi.org/10.1056/NEJM199902253400802

18. Niu MT, Polish LB, Robertson BH, Khanna BK, Woodruff BA, Shapiro CN, et al. Multistate outbreak of hepatitis A associated with frozen strawberries. J Infect Dis. 1992;166(3):518-24. Available from: http://dx.doi.org/10.1093/infdis/166.3.518 PMID:1323618 http://dx.doi.org/10.1093/infdis/166.3.518

19. Ramsay CN, Upton PA. Hepatitis A and frozen raspberries. Lancet. 1989;333(8628):43-4. Available from: http://dx.doi. org/10.1016/S0140-6736(89)91698-X PMID:2563022 http:// dx.doi.org/10.1016/S0140-6736(89)91698-X

20. Reid TM, Robinson HG. Frozen raspberries and hepatitis $A$. Epidemiol Infect. 1987;98(1):109-12. Available from: http:// dx.doi.org/10.1017/S095026880006177X PMID:3030789 http:// dx.doi.org/10.1017/S095026880006177X
21. Calder L, Simmons G, Thornley C, Taylor P, Pritchard K, Greening G, et al. An outbreak of hepatitis A associated with consumption of raw blueberries. Epidemiol Infect. 2003;131(1):745-51. Available from: http://dx.doi.org/10.1017/ So950268803008586 PMID:12948375 http://dx.doi.org/10.1017/So950268803008586

22. Guzman-Herrador B, Jensvoll L, Einoder-Moreno M, Lange $\mathrm{H}$, Myking S, Nygard K, et al. Ongoing hepatitis A outbreak in Europe 2013 to 2014: imported berry mix cake suspected to be the source of infection in Norway. Euro Surveill. 2014;19(15):20775. Available from: http://dx.doi. org/10.2807/1560-7917.ES2014.19.15.20775 PMID:24762662 http://dx.doi.org/10.2807/1560-7917.ES2014.19.15.20775

23. Vaughan G, Xia G, Forbi JC, Purdy MA, Rossi LMG, Spradling $P R$, et al. Genetic relatedness among hepatitis $A$ virus strains associated with food-borne outbreaks. PLoS ONE. 2013;8(11):e74546. Available from: http://dx.doi.org/10.1371/ journal.pone.0074546 PMID:24223112 http://dx.doi. org/10.1371/journal.pone.0074546

24. European Centre for Disease Prevention and Control (ECDC) and European Food Safety Authority. (EFSA). Outbreak of Hepatitis $A$ in EU/EAA countries. Second Update 11 April 2014. Rapid outbreak assessment. Stockholm: ECDC; 2014. Available from: http://www.ecdc.europa.eu/en/publications/Publications/ ROA-Hepatitis $\% 20$ A $\% 2$ ovirus-Italy $\% 2$ olreland $\% 20$ Netherlands $\% 20$ Norway $\% 20$ France $\% 20$ Germany $\% 20$ Sweden\%20United\%20Kingdom\%20-\%2ofinal.pdf 